This manuscript has been accepted by IEEE for publication (C) 2006 IEEE. Personal use of this material is permitted. Permission from IEEE must be obtained for all other uses, in any current or future media, including reprinting/republishing this material for advertising or promotional purposes, creating new collective works, for resale or redistribution to servers or lists, or reuse of any copyrighted component of this work in other works. The full reference is:

\author{
Prevention of Dry-Band Arc Damage on ADSS Cables \\ IEEE Trans DEI 13 Issue 4 (2006) 765-772 \\ S M Rowland \\ DOI: 10.1109/TDEI.2006.1667734
}




\title{
Prevention of Dry-Band Arc Damage on ADSS Cables
}

\author{
S. M. Rowland \\ The School of Electrical and Electronic Engineering \\ The University of Manchester \\ PO Box 88, Manchester, M60 1QD, UK
}

\begin{abstract}
All-dielectric cables separately suspended along high voltage overhead transmission routes are vulnerable to ageing through dry-band arcing. The differences between this process and dry-band arcing on traditional high voltage insulators are reviewed. Solutions to the problem on all-dielectric self supporting (ADSS) cables which involve the introduction of controlled conductivity into the cable are considered. Analysis suggests that arcs which are both electrically stable and spatially confined must be avoided. It is shown that the cable can be protected by limiting either the current or the voltage available to an arc. These considerations reveal that a semiconductive element does not have to cover the whole cable length to provide effective protection against dry-band arcing in this application.
\end{abstract}

Index Terms — ADSS cable, dry-band arc, semiconductive, arc stability.

\section{INTRODUCTION}

ALL-DIELECTRIC self-supporting (ADSS) cables have been widely used to deploy optical fibers on electricity utility overhead networks. Such fibers are used for internal control and communication, and for third-party telecommunications $[1,2]$. To allow live-line installation and prevent induced currents, the industry standard has been to design and install cables with no metallic content. Thus, typical high-voltage span lengths of over $300 \mathrm{~m}$ present additional challenges since metallic strength members may not be used [1]. Both pultruded glass-reinforced plastic and stranded aramid yarns have been used to provide the high strength and tensile modulus required. Figure 1 shows the typical location of an ADSS cable on the lower cross-arm of a twin circuit tower. The cables are normally clamped to the towers using specially designed preformed metallic fittings. These earth the cable surface through traditional overhead line fittings to the tower.

ADSS cables have proved to be very reliable. However, their application is limited by surface damage through electrical activity. The electrical environment can lead to a singular mechanism of ageing identified as dry-band arcing $[3,4]$. The role of corona discharge at the earthed metallic cable clamps is one that continues to be investigated [5].

Several potential solutions have been proposed to this problem $[6,7,8]$, although none other than improving sheath performance has been widely commercialized. Sheath materials are used which resist degradation by dry-band arc activity. Unfortunately the issue of predicting cable lifetime remains unsolved for this approach. Nonetheless, experience suggests that a cable with a good dry-band arc-resistant material is satisfactory for most environments on systems up to $275 \mathrm{kV}[9,10]$ although cables have failed, in extreme circumstances, on much lower voltage lines [11,12]. Thus, there is still debate concerning the true severity of any threat, and consensus has yet to be reached on many aspects of failure.

The rate and form of damage to a cable sheath depends upon its chemistry. For example, PVC is unsuitable because carbon tracks can form on its surface, polyethylene can melt, whilst better materials such as filled EVA can oblate. Specialist filled compounds, designed to prevent tracking and erosion, are now available for sheathing ADSS cables. These materials have significantly enhanced the life expectancy of cables [13,14]. Figures 2 and 3 show pictures of damage from installations on $400 \mathrm{kV}$ and $110 \mathrm{kV}$ lines respectively. Currents seen in service will typically peak at between 1 and 5 $\mathrm{mA}$ in heavily polluted conditions. Unfortunately this is the worst case current for polymer degradation $[15,16]$.

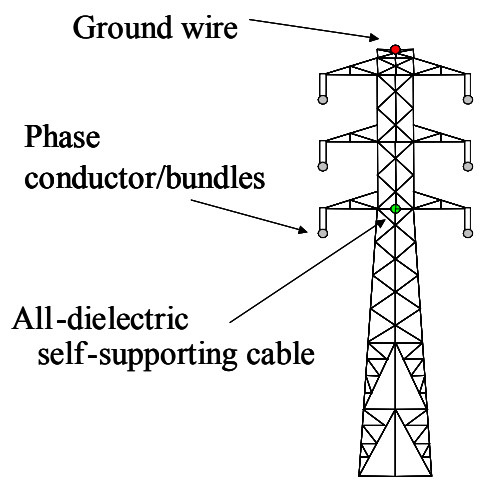

Figure 1. Typical location of an ADSS cable on a twin circuit tower. 


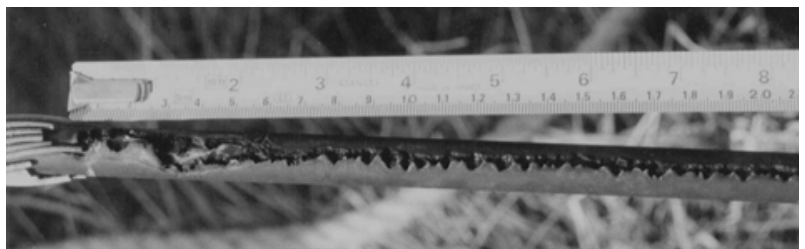

Figure 2. A photograph of cable damaged on a $400 \mathrm{kV}$ line in the UK The deep trough in the sheath is visible on the underside of the cable. The metallic wires on the left of the picture are part of the clamping system.

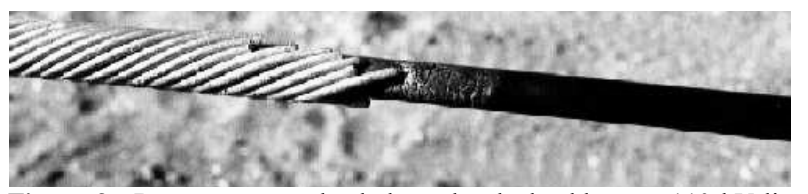

Figure 3. Damage on a polyethylene sheathed cable on a $110 \mathrm{kV}$ line. The metallic wires on the left are part of the cable clamping system at the tower.

\section{DRY-BAND ARCING}

Dry-band arcing is a well established phenomenon on high voltage insulator surfaces. Essentially a conductive wet surface will carry a current if a potential difference is applied. Joule heating will result, adding to other drying processes such as evaporation due to ambient heat. The Joule heating depends upon the resistance per unit length of the moisture, thus if one area of the moisture is slightly more resistive it will generate more heat and so dry even faster and further increase its resistivity, leading to thermal runaway and localized drying. Thus a single break tends to form in the previously continuous moisture film. If the voltage driving the original current creates a large enough field across the dry band, an arc will result.

Arcing is a major issue for traditional insulators because it is a precursor to a flashover event. Once a dry-band arc is formed it is possible for the arc to extend over the moist surface and so completely breach the insulation, resulting in a phase-to-earth arc, which, in the system context, has to be interrupted by removing the phase voltage. For flashover to occur, the field along the arc must be less than the field in the moisture over which it is to extend. This is known as Hampton's criterion [17]. Arc resistance is a strong function of current and so a key feature of insulator design is keeping leakage currents low enough that dry-band extension does not occur. Since a power system will supply a very high current to an outdoor insulator, the geometrical and physical design of the insulator is used to control current flow to a manageable level.

Arcing presents an additional issue to insulator designers because it can age the cable surface. Dry-band arcs and smaller discharges create heat, ozone and acids which can chemically age the surface. This is the major concern for polymeric insulators whose excellent surface properties can be compromised in the long term by such ageing. This is less so for the traditional ceramic materials which are inherently more stable.
The distributed capacitance between an ADSS cable, each phase conductor, the ground wire and the ground results in a field gradient along the dielectric cable. The magnitude of this field also depends on any current drawn by the ADSS cable resulting from its finite resistance. In general this resistance is high $\left(>10^{9} \Omega / \mathrm{m}\right)$ but pollution can reduce it to $10^{6}$ $\Omega / \mathrm{m}$ or less. The potential is at a maximum at mid-span and is at ground potential at the towers, where the cable is grounded by the metallic clamps. This conductivity allows currents to flow along the cable length, and modifies the field gradient on the cable surface. Currents along the cable surface are generally greatest at the clamps and towers. A number of models enabling predictions of currents and fields experienced by cables have been generated $[4,18,19]$ and one of these has been verified on a full-scale installation [19]. More complete models have shown the complexity of the complete picture in which maximum currents are not necessarily seen at the towers in some conditions [20,21].

Dry-band arcs can form on ADSS cables in much the same way as traditional insulators. One major difference is the change in geometry. Normal insulators are designed with shedded surfaces to extend the leakage path. ADSS cables, however, are smooth continuous cylinders of diameters from 12 to over $22 \mathrm{~mm}$. It has been found that dry-bands form of a length similar to the diameter of the cable. Another clear distinction between the case of the ADSS cable and a traditional insulator is that in the traditional application a fixed voltage is directly applied between the two ends from a low impedance source. The current in a dry-band is then limited only by the surface resistance of the insulator. In the case of the ADSS cable the current is capacitively coupled to the cable and so limited by a high impedance source, in addition to its own surface resistance [22,23].

The models and measurements referred to above have shown that in the worst cases currents will not exceed $10 \mathrm{~mA}$ on the ADSS cable, and that the actual value is very dependent on the environment (through the conductivity of the polluted cable). Hampton's criterion can be met on ADSS cables in circumstances of high pollution, allowing an arc to move over the surface of the wet cable. In this case the arc root is no longer restricted to the dry-band edge, and this is probably the reason that testing ADSS cables with currents above $10 \mathrm{~mA}$ has been found to be less damaging than those limited to $4 \mathrm{~mA}[10,24]$. Flashover cannot occur on ADSS cables. However, the presence of dry-band arcing has been shown to cause significant damage to cable sheaths. Indeed the maximum currents expected are those which have been reported previously as being in the range to cause greatest damage to polymeric insulators.

Another feature which is key to understanding the difference in behavior between dry-bands on traditional insulators and on ADSS cables results from the instability of arcs at low currents. A typical arc across a dry-band will have the characteristics shown in Figure 4. In this case the voltage source seen by the arc can supply the current required to maintain the voltage across the resistive arc to keep the arc struck. In the example shown in Figure 5, the arc current is 
limited to less than $1 \mathrm{~mA}$ by the source impedance. In this case once the arc has been struck the voltage source collapses and the arc is extinguished, only to be struck again once the voltage has recovered. Thus many discharges occur within each half cycle rather than a continuous arc. This latter case is referred to as an electrically unstable arc, and has a lower temperature than a stable arc. The transition from an unstable to stable arc occurs at around $1.0 \mathrm{~mA}$ [24].

In analysis of the ageing of the ADSS cable through dryband arcing there are three regions of leakage current to consider: firstly, currents large enough that the arc resistance is low compared to the polluted surface of the insulator so that the arc may extend over the moisture surface - of the order of $10 \mathrm{~mA}$ upwards; secondly, currents insufficient to cause such arc extension but which are nonetheless large enough to cause electrically stable arcing, of the order of $1 \mathrm{~mA}$ upwards; finally, low currents which are unable to generate stable arcs across dry-bands and have the form of Figure 5. In terms of ageing of the polymer it is the second category which must be avoided. At lower currents damage to the cable is small because if the arc is not electrically stable, lower electrical and thermal energy is generated. At higher currents, arcs are not limited to the dry-band edges and so do not concentrate their thermal energy over a small area and again damage is minimal $[10,24]$. It is clear that unlike for traditional insulators, the issue is not one of avoiding dry-band formation, but of avoiding dry-band arcs which are electrically stable and spatially confined. Practically the issue is one of reducing an arc current experienced by the cable to less than $1 \mathrm{~mA}$.

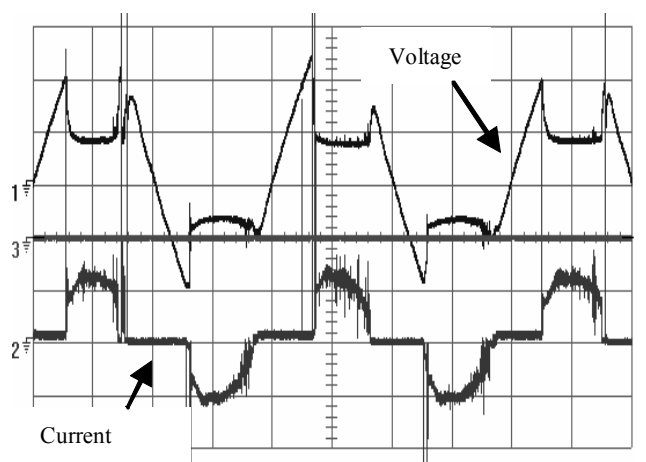

Figure 4. Typical voltage and current of a stable dry-band arc.

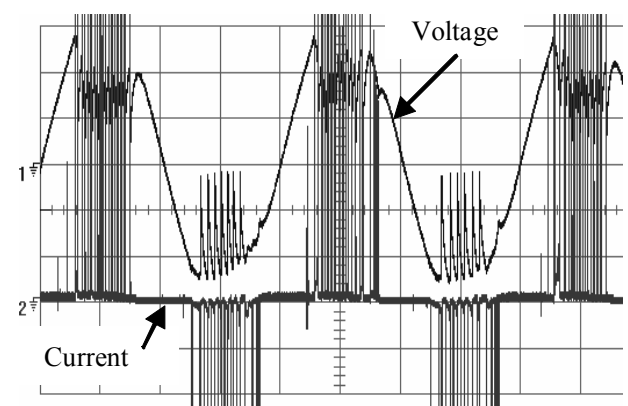

Figure 5. Voltage and current of an unstable dry-band arc.
Table 1. The key differences between a dry-band arc on a traditional insulator and an ADSS cable.

\begin{tabular}{|l|l|l|}
\hline \multicolumn{1}{|c|}{ Issue } & \multicolumn{1}{|c|}{ Traditional Insulator } & \multicolumn{1}{c|}{ ADSS Cable } \\
\hline $\begin{array}{l}\text { Main concern over } \\
\text { dry-band arc } \\
\text { formation: }\end{array}$ & $\begin{array}{l}\text { Leads to flashover of } \\
\text { ceramic insulators and } \\
\text { ageing of polymeric } \\
\text { insulators }\end{array}$ & Sheath degradation \\
\hline $\begin{array}{l}\text { Dry-band arc current } \\
\text { limited is by: }\end{array}$ & Surface resistance & $\begin{array}{l}\text { Surface resistance and } \\
\text { capacitive coupling }\end{array}$ \\
\hline Voltage available: & $\begin{array}{l}\text { Limited by system } \\
\text { voltage }\end{array}$ & $\begin{array}{l}\text { Controlled by line } \\
\text { capacitances, typically } \\
10 \% \text { of system voltage }\end{array}$ \\
\hline $\begin{array}{l}\text { Maximum current } \\
\text { available: }\end{array}$ & Effectively unlimited & \begin{tabular}{l} 
Typically up to $6 \mathrm{~mA}$ \\
\hline
\end{tabular}
\end{tabular}

Table 1 summarizes the differences between a dry-band arc on a traditional insulator and one on an ADSS cable.

Figure 6 illustrates an example of the space potential in which the cable sits at mid-span. The use of mid-span equipotential contours has become standard practice to identify locations of low space potential where an ADSS cable can be installed, thereby minimizing the current available to an arc. Changes to phase arrangements and outages need to be considered since these may affect the mid-span potential significantly. A heuristic has been developed so that a space potential contour of $12 \mathrm{kV}$ is often considered to represent a boundary, outside of which an ADSS cable could become susceptible to damage by dry-band arcing [25]. Guidelines relating to the geographical location of a proposed ADSS installation have also been created in an attempt to ensure that the currents on a cable are acceptably low [26]. Typically, in order to determine the minimum cable conductivity expected it is necessary to check whether the line is located near to a coastline or a source of industrial pollution, as it is known that both of these situations can contribute to ADSS cables becoming reasonably conductive, and hence susceptible to dry-band arc-related degradation.

Figure 7 shows the impact of the pollution resistivity on the maximum current seen on a symmetrically phased, twin circuit $400 \mathrm{kV}$ tower of the type depicted in Figure 1. Only in extreme circumstances of pollution will the resistance fall to these levels; however the currents required to achieve dryband arcing can occur.

\section{THE USE OF CONDUCTIVITY TO CONTROL STRESS}

The introduction of semiconductive glazes to reduce discharges on ceramic insulation systems is well established, although concerns remain over their stability in the long term $[27,28]$. The semiconducting glaze has two functions. Firstly, it draws a continuous current of the order of $1 \mathrm{~mA}$ which provides continuous heating, thereby increasing the temperature of the insulator and keeping it dry. Secondly, the glaze promotes a uniform field over the insulator length and in particular reduces the resistance of any dry-band 


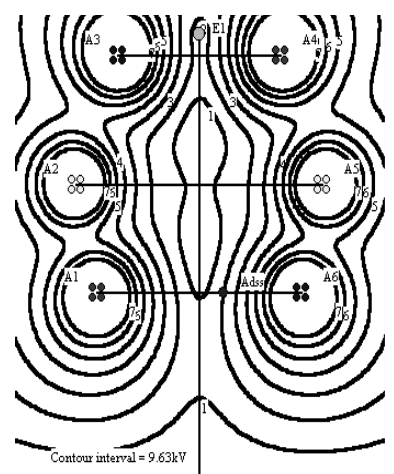

Figure 6. Space potential plots across a mid-span plan perpendicular to the conductors on a $400 \mathrm{kV}$ line. The contour intervals are $10 \mathrm{kV}$. The phase arrangement is $\mathrm{ABC}, \mathrm{CBA}$.

which does form, thereby reducing the positive feedback cycle of drying, and reducing the field across the dry-band available for arcing. It is quite possible that the negative temperature coefficient of resistivity also contributes to preventing arc formation [29].

It has previously been argued that by introducing conductivity into the ADSS cable stresses can be managed and so arcs suppressed $[6,7,18]$. Suggestions of linear resistance for cables have been between $10^{6}-10^{9} \Omega / \mathrm{m}$; values which shall be shown to be too high. These values were probably derived before measurements showed that linear resistance of a heavily polluted cable can reach as low as $2 \times 10^{5} \Omega / \mathrm{m}$.

Figure 8 shows schematically a dry-band of length $d$, formed on a surface of linear resistance $r_{s} \Omega / m$. Either side of the dry-band is pollution of linear resistance $r_{p} \Omega / m$. In reality the value of $r_{p}$ will depend on the state of drying of the moisture. However, the assumption here is that this value is uniform along the cable surface. The current, i, flowing through this section of cable is not influenced by the small change in total resistance presented by the formation of the dry-band. In the absence of a dry-band the voltage per unit length on the cable is $i .\left(r_{p} / / r_{s}\right)$, whereas in the dry-band region the voltage gradient is $i . r_{s}$, and the voltage across the

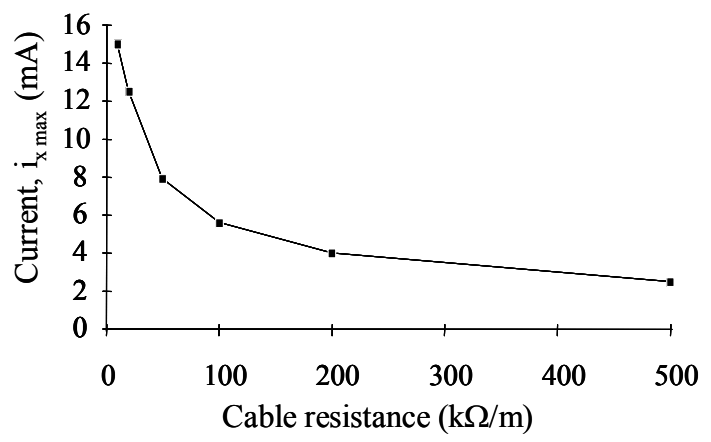

Figure 7. Currents at the tower as a function of cable resistance per unit length on a symmetrical $400 \mathrm{kV}$ line. dry-band is i.r. $r_{s} \cdot d$. The current itself will be a function of $\left(r_{p} / / r_{s}\right)$ the net resistance per unit length of the cable. If $r_{s}>>r_{p}$ $r_{p}$ then $r_{s}$ has little impact on the voltage across the dry-band. If $r_{s}<<r_{p}$ then the voltage gradient will not be increased by the dry-band. A low value of $r_{s}$ also increases the value of $I$, as in Figure 7.

The electrical field across the dry-band of length d depends upon the resistance of that band $r_{s}$.d. It is the high resistance of that region compared to the rest of the cable which leads to a high field across the band, and the resultant arc. If a dryband were to occur on a conductive cable, the conductive component from the cable is in parallel with the dry-band, thus the electrical stress and so the total voltage dropped across it are reduced, thereby preventing arcing occurring.

It is, however, the dielectric nature of the cable which allows live-line installation and ensures clearances are maintained. There is therefore an operational limit on the cable conductivity. Thus simply producing a cable with a sheath made from a standard 'semiconducting' carbon-loaded polymer is not a solution. Such materials typically have resistivity of $5 \Omega \mathrm{m}$ and, used as a sheath of radial sheath thickness of $1.5 \mathrm{~mm}$ on a cable of $14 \mathrm{~mm}$ diameter, give a cable of resistance per unit length $85 \mathrm{k} \Omega / \mathrm{m}$, much too conductive to be treated as insulating. Moreover, any region of the cable with an anomalously high resistance due to manufacturing defects would threaten to create conditions of thermal runaway, since the cable would continuously draw current controlled by the average resistance per unit length (6 $\mathrm{mA}$ in the case shown in Figure 7). Thus a poorly manufactured conductive cable will pose a more severe and immediate problem than a dielectric one.

If the minimum stable dry-band length is controlled by the cable diameter and is taken as $10 \mathrm{~mm}$, and the maximum current on a heavily polluted cable is $5 \mathrm{~mA}$, then a cable with intrinsic resistance per unit length $1 \mathrm{M} \Omega / \mathrm{m}$ could never have more than $5 \mathrm{kV} / \mathrm{m}$ along a dry section. This is equivalent to $50 \mathrm{~V}$ over a $10 \mathrm{~mm}$ dry-band, a voltage too low to cause arcing. The maximum current of $5 \mathrm{~mA}$ produces Joule heating in the sheath of $25 \mathrm{~W} / \mathrm{m}$. The balance of providing enough conductivity to prevent arcing, retaining the cable's dielectric nature for safety, and dissipating heat means that only a narrow window of cable resistivity is acceptable, and as stated previously, the values required make the product hard to fabricate reliably.

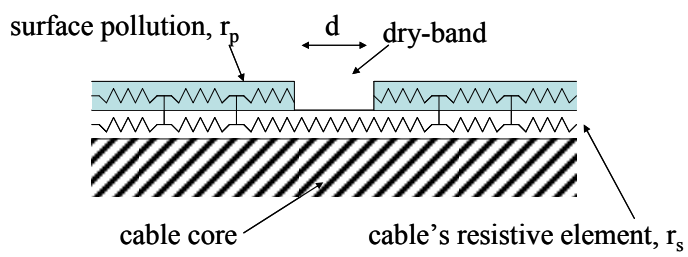

Figure 8. A schematic of a dry band. 


\section{AN ALTERNATIVE SOLUTION}

An alternative to making a cable with controlled resistivity is to introduce the conductivity after the dielectric cable is installed. One such system consists of a rod of controlled resistance per unit length which is attached to a previously installed ADSS cable. The rod covers the first $50 \mathrm{~m}$ of the cable adjacent to the tower, and is earthed at the tower. The system has the added benefit that the rod is held on by simple clips that enable it to be manually pushed on to the cable manually $[19,30]$. The clips holding the rod in place are spaced every $30 \mathrm{~cm}$ and are much more conductive than the rod. Since the rod is separate from the cable, it can run at higher temperatures, dissipate heat better and gives greater opportunity for quality control in manufacturing. Figure 9 shows the installed rod schematically.

Over the conductive part of the cable, dry-band arcing is controlled in the manner described previously. However, a dry band can occur beyond the rod-covered region. In this region substantial voltages are still available but the current is limited, and so the damage caused by an arc is limited.

The maximum current seen in the whole system will be at the clamp, and this is shared between the rod and the cable surface. Each of the drawings in Figure 10 illustrates a different situation to be considered in the design. Here the cable is represented as a substrate for conductive pollution (moisture). The rod has a linear resistance of $R_{r}$ per unit length and the cable (including pollution) has a resistance $R_{c}$ per unit length. The first schematic defines zone 1 as that part of a half-span covered by the rod, and zone 2, as that region beyond the rod end. Figure 10a shows a dry, high resistance cable with a resistive rod. The maximum current in this system must be at $\mathrm{X}$, the current accumulated over Zone 1 . This is the minimum current $\left(\mathrm{i}_{\mathrm{x} \text { dry }}\right)$ which the resistive rod will see at this point and must be endured over its lifetime. The heat generated by Joule heating is given by $\left(i_{x d r y}\right)^{2} R_{r}$. $i_{x \text { dry }}$ is a function of $R_{r}$ and the rod length. Figure $10 \mathrm{~b}$ shows the

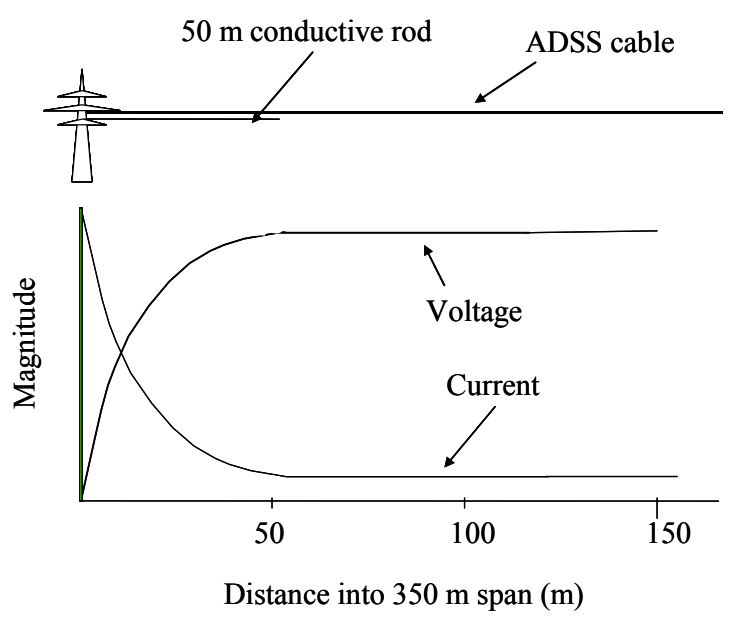

Figure 9. The rods cover the regions of cable where significant currents can occur in the event of high pollution. situation when the cable is completely wet. It should be noted that if the moisture imparts a resistance per unit length $R_{2}$ on zone 2 , the resistance in zone $1, R_{1}$, is $\left(R_{r} / / R_{2}\right)$, not simply $R_{r}$, the rod's resistance per unit length. The current is therefore greater than in case (a) above. This current at $\mathrm{X}$ will be shared between the rod and the moisture. Thus it must be ensured that the rod's share of the current is still within its thermal limit, just as for the dry case. As previously, the current is greatest at $\mathrm{X}$, so that a dry-band is most likely to form there first. Dry-band formation will be slowed by the presence of the rod. In this condition of a completely wet cable, the maximum current possible is flowing to earth. That the current $i_{x \text { wet }}$ is a function of $R_{r}$, the rod length, and through $\mathrm{R}_{2}$, is dependent upon pollution levels.

Figure 10c shows a dry band formed at X. This has two implications. One is an increased voltage gradient across that gap. This is because the current is virtually unaffected by the local increase in resistance. If the voltage across the gap (dryband) is sufficient, an arc will occur. The maximum voltage gradient is given by the product of $i_{x}$ wet and $R_{r}$. The power generated per unit length in the resistive rod, at the dry-band, in the absence of an arc, is given by the product of $i_{x \text { wet }}{ }^{2}$ and $\mathrm{R}_{\mathrm{r}}$. The voltage available for an arc across the dry band is given by the product of $i_{x \text { wet }}, R_{r}$ and the dry band width. The current available for an arc in this location is the share of $i_{x \text { wet }}$ carried on the cable sheath, rather than in the rod $i_{c}$ wet (these are electrically parallel resistive components). In addition to any long-term ageing effect on the rod materials, short-term heating may also affect the resistance of the rod. Typically, heating will increase $R_{r}$ in the materials used, so thermal instability can arise if material selection is inappropriate. Figure 10d shows a dry band formed within the length of the rod, at $\mathrm{Y}$. If $\mathrm{R}_{\mathrm{r}}$ is well controlled and constant along the rod length, this situation must be less onerous than that of a dry band at $\mathrm{X}$, since the current must be lower. The case shown in Figure 10e is similar to that of Figure 10a. In this case the region covered by the rod has dried, but the remainder of the cable is wet. The primary difference is that a current, $i_{z}$, can now flow through the tip of the rod from the rest of the span at point $\mathrm{Z}$. Therefore, the current at $\mathrm{X}$ will also increase.

Figure 10f shows the condition which is most likely to give rise to damaging dry-band arcing if the system is poorly designed. This was experienced during product development. For example, if the rod is very conductive (i.e. if $R_{r}$ tends to metallic levels), the situation is unchanged from that of a wholly dielectric system; it is simply as if the clamp had been shifted up the cable. The parameter determining whether or not a damaging arc can form is the current, $i_{z \text { wet }}$, available if no gap were present, as in the case of Figure 11e. This is the current available to drive an arc where there is no protection from the rod. If $i_{z \text { wet }}$ is kept sufficiently low, any arc activity will not be severe enough to damage the cable. This is the basis of the rod's efficacy.

Five requirements can be identified to ensure that the system, in all the states illustrated in Figure 10, is not compromised. These requirements are: 
I a maximum acceptable continuous power generation in the rod so that it does not age unacceptably, $\mathrm{P}_{\mathrm{r} \text { max }}$. This value depends upon the rod design and material ageing properties:

$$
\left(\mathrm{i}_{\mathrm{x} \text { dry }}\right)^{2} \mathrm{R}_{\mathrm{r}}<\mathrm{P}_{\mathrm{r} \max }
$$

II a maximum acceptable short-term power generation in the rod to prevent physical damage or change its resistance unacceptably, $\mathrm{P}_{\mathrm{r} \text { limit }}$; this will also depend upon the rod design and materials:

$$
\left(\mathrm{i}_{\mathrm{x} \text { wet }}\right)^{2} \mathrm{R}_{\mathrm{r}}<\mathrm{P}_{\mathrm{r} \text { limit }}
$$

III a maximum current on the cable surface under the rod in zone 1, so damaging dry-band arcing damage does not occur. Thus at $\mathrm{X}$, the share of $\mathrm{i}_{\mathrm{x} \text { wet }}$ under the rod on the cable surface, $i_{x c}$ wet, is insufficient to cause damaging dry-band arcing:

$$
\mathrm{i}_{\mathrm{xc} \text { wet }}<\mathrm{i}_{\text {slimit }}
$$

IV a maximum acceptable voltage gradient on the rod so arcing cannot occur, $\mathrm{E}_{\mathrm{r} \text { limit }}$. $\mathrm{so}$ that

$$
\mathrm{i}_{\mathrm{x} \text { wet }} \mathrm{R}_{\mathrm{r}}<\mathrm{V}_{\mathrm{r} \text { limit }}
$$

a maximum acceptable current at the rod tip, $i_{\text {slimit }}$, so that dry-band arcing at this location has insufficient current to damage the cable. $\mathrm{i}_{\mathrm{s} \text { limit }}$ depends upon the cable sheath material and is used in condition III:

$$
\mathrm{i}_{\mathrm{z} \text { wet }}<\mathrm{i}_{\mathrm{s} \text { limit }}
$$

The following are experimentally-determined limiting parameters for a particular resistive rod design:

$$
\begin{aligned}
& \mathrm{P}_{\mathrm{r} \max }=10 \mathrm{~W} / \mathrm{m} \\
& \mathrm{P}_{\mathrm{r} \text { limit }}=40 \mathrm{~W} / \mathrm{m} \\
& \mathrm{E}_{\mathrm{r} \text { limit }}=10 \mathrm{kV} / \mathrm{m}
\end{aligned}
$$

For most dry-band arc resistant materials tested:

$$
\mathrm{i}_{\mathrm{s} \text { limit }}=1.0 \mathrm{~mA}
$$

For standard PE based sheath materials:

$$
\mathrm{i}_{\mathrm{s} \text { limit }}=0.2 \mathrm{~mA}
$$

Conditions (9) and (10) are derived from many laboratory tests and from installation measurements [10,19,24], but are critical to the analysis. In applications to date more conservative values have been used.

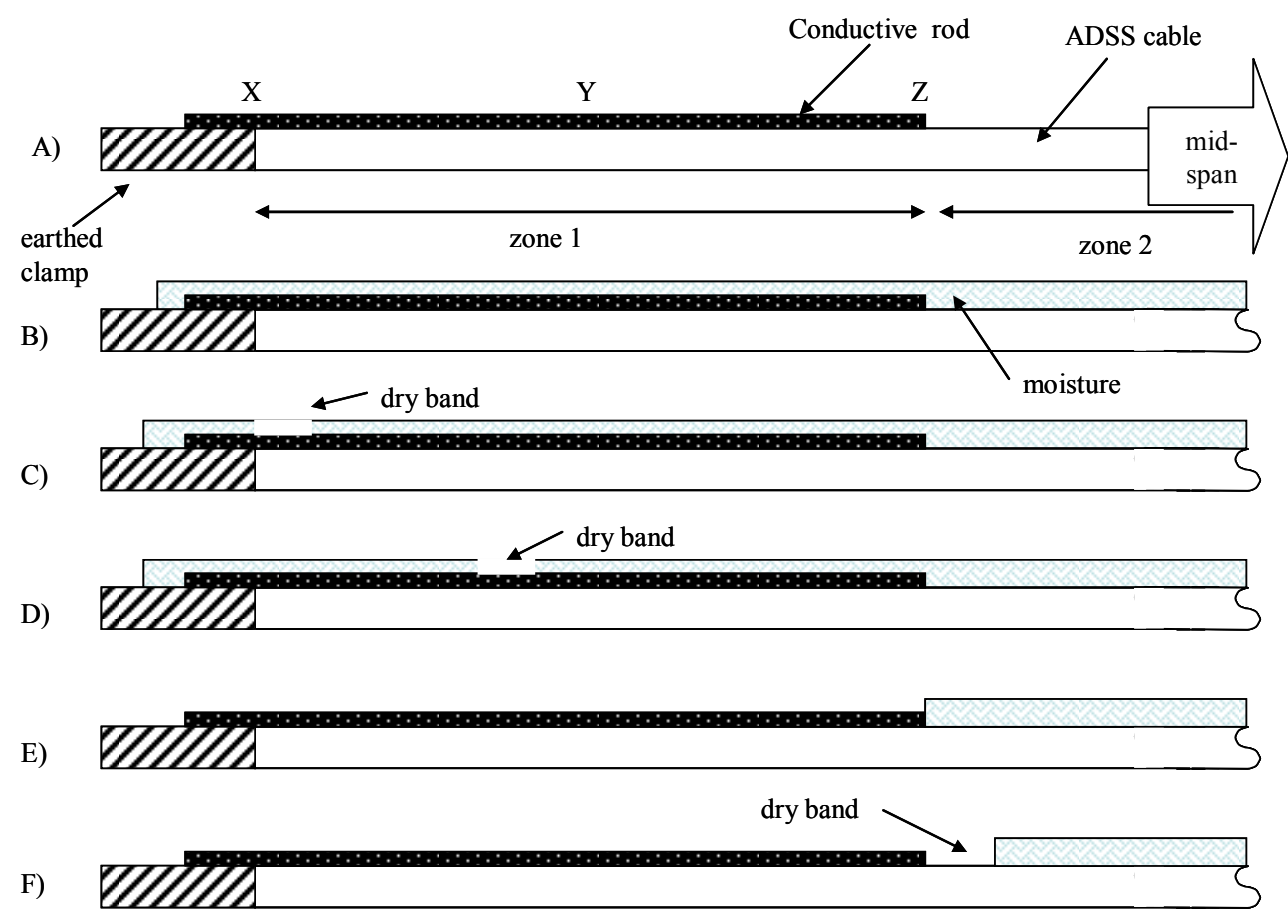

Figure 10. Schematic showing the different conditions experienced by the system. The length of cable covered by the rod is called zone 1 , and the rest of the span, zone 2 . 
Table 2. Comparison of spans of differing system voltages. In each case the resistive rod is $50 \mathrm{~m}$ long, and the span length $366 \mathrm{~m}$

\begin{tabular}{|c|c|c|c|c|c|c|c|c|c|}
\hline $\begin{array}{c}\text { System } \\
(\mathrm{kV})\end{array}$ & $\begin{array}{l}\mathrm{R}_{\mathrm{r}} \\
(\mathrm{k} \Omega / \mathrm{m})\end{array}$ & $\begin{array}{l}\mathrm{R}_{2} \\
(\mathrm{k} \Omega / \mathrm{m})\end{array}$ & $\begin{array}{l}\mathrm{i}_{\mathrm{x} \text { dry }} \\
(\mathrm{mA})\end{array}$ & $\begin{array}{l}\mathrm{i}_{\mathrm{x} \text { dry }}{ }^{2} \mathrm{R}_{\mathrm{r}} \\
(\mathrm{W} / \mathrm{m})\end{array}$ & $\begin{array}{l}\mathrm{i}_{\mathrm{x} \text { wet }} \\
(\mathrm{mA})\end{array}$ & $\begin{array}{l}\mathrm{I}_{\mathrm{c} \text { wet }} \\
(\mathrm{mA})\end{array}$ & $\begin{array}{l}\mathrm{i}_{\mathrm{x} \text { wet }} \mathrm{R}_{\mathrm{r}} \\
(\mathrm{W} / \mathrm{m})\end{array}$ & $\begin{array}{l}\mathrm{i}_{\mathrm{x} \text { wet }} \mathrm{R}_{\mathrm{r}} \\
(\mathrm{V} / \mathrm{m})\end{array}$ & $\begin{array}{l}\mathrm{i}_{\mathrm{z} \text { wet }} \\
(\mathrm{mA})\end{array}$ \\
\hline 400 & 500 & 500 & 2.9 & 4.2 & 3.4 & 1.7 & 5.8 & 1700 \\
\hline 275 & 500 & 500 & 2.4 & 2.9 & 2.8 & 1.4 & 3.9 & 0.88 \\
\hline 132 & 500 & 500 & 0.72 & 0.26 & 0.83 & 0.42 & 0.34 & 415 & 0.69 \\
\hline
\end{tabular}

Table 3. Effect of resistive rod resistance on a symmetrically phased $400 \mathrm{kV}$ system.

\begin{tabular}{|c|c|c|c|c|c|c|}
\hline $\mathrm{R}_{\mathrm{r}}(\mathrm{k} \Omega / \mathrm{m})$ & $\mathrm{i}_{\mathrm{zwet}}(\mathrm{mA})$ & $\mathrm{i}_{\mathrm{x} \text { wet }}(\mathrm{mA})$ & $\mathrm{i}_{\mathrm{x} \text { dry }}{ }^{2} \mathrm{R}_{\mathrm{r}}(\mathrm{W} / \mathrm{m})$ & $\mathrm{i}_{\mathrm{x} \text { wet }}{ }^{2} \mathrm{R}_{\mathrm{r}}(\mathrm{W} / \mathrm{m})$ & $\mathrm{i}_{\mathrm{x} \text { wet }} \mathrm{R}_{\mathrm{r}}(\mathrm{V} / \mathrm{m})$ & $\mathrm{I}_{\mathrm{xc} \text { wet }}(\mathrm{mA})$ \\
\hline 200 & 2.2 & 8.4 & 6.9 & 14 & 1700 & 4.2 \\
\hline 400 & 1.2 & 7.6 & 7.9 & 23 & 3000 & 5.1 \\
\hline 600 & 0.8 & 7.3 & 8.2 & 33 & 4400 & 5.5 \\
\hline 800 & 0.5 & 7.1 & 8.3 & 40 & 5700 & 5.7 \\
\hline 1000 & 0.4 & 7.0 & 8.3 & 48 & 7000 & 5.8 \\
\hline 1200 & 0.3 & 6.9 & 8.3 & 57 & 8200 & 5.9 \\
\hline
\end{tabular}

Table 2 shows some calculated values for typical geometry twin circuit towers. It should be noted that $R_{r}$ is quoted in Table 2, not $R_{1} . R_{1}$ varies, depending on whether the cable is wet or dry. The analysis shows the impact of $50 \mathrm{~m}$ rods of $500 \mathrm{k} \Omega / \mathrm{m}$, and assumes pollution that gives a minimum resistance on the cable of $500 \mathrm{k} \Omega / \mathrm{m}$. The location of the ADSS cable is that shown in Figure 1. It should be noted that differential sag between conductors and the ADSS cable can significantly affect these values and so care must be taken with generalization of such data. On this basis, by considering conditions (6) to (10), if rods of $R_{r}=500 \mathrm{k} \Omega / \mathrm{m}$ are used the problem of dry-band arcing is overcome for all cases since $\mathrm{i}_{\mathrm{zwet}}<1 \mathrm{~mA}$. This is marginal for the $400 \mathrm{kV}$ system and additional tests might be advisable on the sheath material to ensure the value of $1 \mathrm{~mA}$ is appropriate. It might be considered that the value of $I_{c}$ wet $=1.7 \mathrm{~mA}$ presents an issue, since this implies that an arc current of greater than $1 \mathrm{~mA}$ is available parallel to the rod. However the voltage available at this location $(1700 \mathrm{~V} / \mathrm{m})$ is not sufficient to enable arcing so a threat does not exist.

For a symmetrically phased $400 \mathrm{kV}$ tower, Table 3 shows the effect of $\mathrm{R}_{\mathrm{r}}$, for a $50 \mathrm{~m}$ long rod on (i) the continuous power generated in the rod, $i_{\mathrm{rdry}}^{2} \mathrm{R}_{\mathrm{r}}$, (ii) the short-term maximum power generated in the rod in conditions of extreme pollution, $i_{x \text { wet }}{ }^{2} R_{r}$, (iii) the maximum voltage gradient along the rod, $i_{x w e t} R_{r}$, (iv) the current available for arcing at the end of the rod, $i_{z}$ wet, and (v) the maximum current on the cable underneath the rod at $\mathrm{X}, \mathrm{i}_{\mathrm{x} \text { wet, }}$ assuming pollution on the cable of $200 \mathrm{k} \Omega / \mathrm{m}$. From this analysis, it can be seen that as the resistance of the rod increases, the current at its tip is reduced. Only if $R_{r}>500 \mathrm{k} \Omega / \mathrm{m}$ is $i_{z}$ max low enough to suggest the system would (equation 9). However only at $800 \mathrm{k} \Omega / \mathrm{m}$ and below is the power dissipation satisfactory. Also the current on the wet cable at the tower, under the rod ( $\mathrm{I}_{\mathrm{c} \text { wet }}$ ) is large in any circumstances. The voltage gradient on a rod of resistance $600 \mathrm{k} \Omega / \mathrm{m}$ is $3000 \mathrm{~V} / \mathrm{m}$, (the product of resistance and $5 \mathrm{~mA}$ ). This is a significant voltage gradient and we would expect arcing to occur parallel to the rod, so we can not find satisfactory solution in this case. The combination of symmetric phasing and very high pollution levels presents too severe an environment. From this we see that knowledge of the pollution levels is critical in the application of ADSS cables and the rod.

\section{CONCLUSIONS}

Although the origin of dry-band arcing is the same for traditional insulators and ADSS cable the properties of the dry-band arcs are different. This is mainly because of the impedance of the current source. In the case of an ADSS cable, flashover is not a concern, but damage to the cable as a result of arcs in the range 1.0 to $6 \mathrm{~mA}$ limits their application. However if the arc currents on the cable can be reduced to less than $1 \mathrm{~mA}$ (the precise value varies with sheath material) the impact of the presence of a dry-band arc is minimized.

Protection of an ADSS cable can be achieved without preventing dry-band arcs, but by reducing currents available to arcs so that they become electrically unstable and therefore less severe. The resulting change in design parameters allows a practical solution to the problem of dry-band arcing on ADSS cables to be developed. An engineered solution based on the application of a rod of controlled resistivity to a previously installed ADSS cable has been described along with its electrical functionality. The limits of applicability of this solution have been discussed, and are found to be controlled by the level of short-term ambient pollution in the environment. Typically a rod of $50 \mathrm{~m}$ long and $1 \mathrm{M} \Omega / \mathrm{m}$ can provide solutions to situations otherwise untenable for ADSS cables.

\section{ACKNOWLEDGMENT}

The author would like to thank Hulya Kirkici for her advice in helping to shape this paper, and numerous colleagues at Corning who made the idea a reality.

\section{REFERENCES}

[1] G. F. Moore, Ed., Electric Cables Handbook, 3rd Edition, Ed, Blackwell Science, Part 7, "Optical Fibres in Power Transmission Systems," Chapters 47-52, pp. 685-752, 1997.

[2] S. C. Sharma, "Solution for fibre optic cables installed on overhead power transmission lines. A review", IETE Technical Review, Vol. 11, pp. $215-222,1994$ 
[3] C. N. Carter, "Dry Band Electrical Activity on Optical Cables Strung on Overhead Power Lines", Proc. 37th International Wire and Cable Symposium, pp. 117-121, 1988.

[4] C. N. Carter and M. A. Waldron, "Mathematical model of dry-band arcing on self-supporting, all-dielectric optical cables strung on overhead power lines", IEE Proc. C, Vol. 139, pp. 185-196, 1992.

[5] G. G. Karady, G. Besztercey, and M. W. Tuominen, "Corona caused deterioration of ADSS fiber-optic cables on high voltage lines," IEEE Trans. Power Delivery, Vol. 14, pp. 1438-1447, 1999.

[6] C. N. Carter, "Arc Controlling Devices for use on Self-supporting Optical Cables”, IEE Proc. A, Vol. 140, pp. 357-361, 1993.

[7] U. H. P. Oestreich and H. M. Nassar, "Self-supporting dielectric fibre optical cables in high voltage lines", 37th Proc. International Wire and Cable Symposium, pp. 79-82, 1988.

[8] G. Karady, D. Srinivasa, M. Reta-Hermandez, M Touminen, D. Torgerson, and B. Tan, "A mitigation method for dry-band arcing caused deterioration of ADSS fibre optical cables", IEEE Power Eng. Society, Winter Meeting, Vol. 4, pp. 2391-2396, 2000.

[9] J. Peacock and J. C. G. Wheeler, "The development of aerial fibre optic cables for operation on $400 \mathrm{kV}$ power lines", IEE Proc. A, Vol. 139, pp 304-313, 1993.

[10] S. M. Rowland and F. Easthope, "Electrical ageing and testing of dielectric self-supporting cables for overhead power lines", IEE Proc. A Vol. 140, pp. 351-356, 1993.

[11] F. Kaidanov, R. Munteanu, and G. Sheinfain, "Damages and destruction of fiber optic cables on $161 \mathrm{kV}$ overhead transmission lines", IEEE Electrical Insulation Magazine, Vol. 16, pp. 16-23, 2000.

[12] S. M. Rowland, N. R. Haigh and O. de la Cerda, "The installation of a system on an all-dielectric self-supporting cable to prevent failure through dry-band arcing on HV transmission lines", 14th International Symposium on High Voltage Engineering, F-56, 2005.

[13] J. C. G. Wheeler, M. J. Lissenburg, J. D. S. Hinchecliffe and M. E. Slevin, "The development and testing of a track-resistant sheathing material for aerial optical fibre cables", $5^{\text {th }}$ IEE Conference of Dielectric Materials Measurements and Applications, pp. 73-76, 1988.

[14] S. M. Rowland, "Sheathing materials for dielectric, aerial, selfsupporting cables for application on high voltage power lines", 6th IEE Conference on Dielectric Materials, Measurements and Applications, pp. 53-56, 1992.

[14] M. J. Billings and K. W. Humphreys, "An outdoor tracking and erosion test of some epoxide resins", IEEE Trans. EI Vol. 3, pp. 62-70, 1968.

[15] A. Bradwell and J. C. G. Wheeler, "Evaluation of plastic insulators for use on British Railways $25 \mathrm{kV}$ overhead line electrification", IEE Proc. B, Electr. Power Appl., Vol. 129, pp. 101-110, 1982.

[16] B. F. Hampton, "Flashover mechanism of polluted insulation", Proc. IEE 1964, Vol. 111, pp. 985-989, 1964

[17] A. G. W. M. Berkers and J. M. Wetzer, "Electrical stresses on a selfsupporting metal-free cable on high voltage networks", IEE Conference on Dielectric Materials, Measurements and Applications, pp. 69-72, 1988
[18] N. R. Haigh, S. M. Rowland, A. J. Taha and C. N. Carter, "A fully instrumented installation and trial of a novel all-dielectric selfsupporting cable system for very high voltage overhead power lines", 45th Proc. International Wire and Cable Symposium, pp. 60-67, 1996.

[19] M. W. Tuominen and R. G. Olsen, "Electrical design parameters of alldielectric-self-supporting fibre optic cables", IEEE Trans. Power Delivery, Vol. 15, pp. 940-947, 2000.

[20] S. M. Rowland, K. Kopsidas and I. Cotton, "Modeling of currents on long span, dielectric cables on HV overhead lines", IEEE Trans. Power Delivery, Submitted for publication.

[21] Q. Huang, G. G. Karady, B. Shi and M. Tuominen, "Study on development of dry band on ADSS fibre optical cable", IEEE Trans. DEI Vol. 12, pp. 487-495, 2005

[22] Q. Huang, G. G. Karady, B. Shi and M. Tuominen, "Numerical simulation of dry-band arcing on the surface of ADSS fibre optic cable", IEEE Trans. DEI Vol. 12, pp. 496-503, 2005

[23] S. M. Rowland and I. V. Nichols, "Effects of dry-band arc current on ageing of self-supporting dielectric cables in high fields", IEE Proc. Sci. Meas. Technol., Vol. 143, pp. 10-14, 1996.

[24] IEEE draft Specification 1222P Standard for Self-Supporting Fibre Optic Cable (ADSS) for use on Overhead Utility Lines, 1995.

[25] C. N. Carter, J. Deas, N. R. Haigh and S. M. Rowland, "Applicability of all-dielectric self-supporting cable system to very high voltage overhead power lines", 46th Proc. International Wire and Cable Symposium, pp. 624-631, 1997.

[26] P. J. Lambeth, "The use of semiconducting glaze insulators", Electra Vol. 86, pp. 89-106, 1983

[27] H. Ullrich and S. M. Gubanski, "Electrical Characterization of New and Aged Semiconducting Glazes", IEEE Trans. DEI, Vol.12, pp.24-33, 2005 .

[28] S. Matsui, Y. Suzuki, M. Nakashima, F. Kasaki and O. Fujii, E. Matsuda, "State of the art of semiconducting glazed insulators for transmission lines in heavily contaminated areas", Proc. $5^{\text {th }}$ Int. Conf. on Properties and Applications of Dielectric Materials, pp.726-729, 1997.

[29] A. J. Taha, I. V. Nichols, C. A. Platt and S. M. Rowland, "A novel system for the installation of all-dielectric self supporting optical cables on high voltage overhead power lines", 44th Proc. International Wire and Cable Symposium, pp. 171-177, 1995.

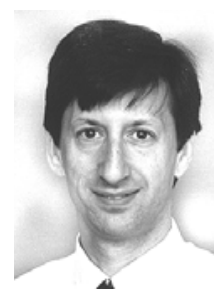

Simon M. Rowland (M'05) was born in London, England. He completed his BSc in Physics at UEA and his $\mathrm{PhD}$ at London University. He was awarded the IEE Duddell Premium in 1994 he became a FIEE in 2000. He has worked for many years on dielectrics and their applications. He has also been Operations and Technical Director in a multinational manufacturing company. $\mathrm{He}$ joined The School of Electrical and Electronic Engineering in The University of Manchester as a Senior Lecturer in 2003 